\title{
ANALYTICAL MODEL FOR THE PREDICTION OF THE ELASTIC RESPONSE OF CURVED T-STUBS
}

\author{
Andrej MUDROV ${ }^{1^{*}}$, Jean-Pierre JASPART ${ }^{2}$, \\ Adrien CORMAN ${ }^{2}$, Antanas ŠAPALAS ${ }^{1}$ \\ ${ }^{1}$ Department of Steel and Composite Structures, Faculty of Civil Engineering, \\ Vilnius Gediminas Technical University, Sauletekio al. 11, LT-10223, Vilnius, Lithuania \\ ${ }^{2}$ Department ArGEnCo, University of Liège, Quartier Polytech 1, 9 \\ Allée de la Découverte, 4000 Liège, Belgium
}

Received 31 May 2021; accepted 23 June 2021

\begin{abstract}
Composite steel-concrete columns utilise the advantages of both materials, by combining high strength and ductility of steel with the compressive strength of the concrete. But the wide adaptation of composite structures is limited, mainly because of the lack of cheap and easy to construct connections, as many of which require costly and timeconsuming on-site welding, when circular concrete filled steel tubes (CFST) are adopted. New connections, like those incorporating the use of blind bolts and curved end-plates, may represent a valuable alternative. Such joints can be adapted to circular CFST to eliminate on-site welding, but they require the creation of new curved T-stub components. This paper proposes an analytical model for the evaluation of bolt forces in the curved T-stubs within the elastic range. The model is then validated against experimental results of joints between circular CFST columns and steel beams, with both preloaded and snug tightened bolts. Analytical model shows good agreement with experimental data, but needs further development to take into account the prying forces.
\end{abstract}

Keywords: curved end plate, analytical model, composite steel-concrete, CFST, beam-to-column connection, experimental investigation.

\section{Introduction}

Steel-concrete composite structures offer high strength, stiffness and superior ductility. But they are still widely unused and considered to be an exceptional, costly solution. Particularly, this can be seen in the case of circular composite columns which exhibit greater compressive strength, as a circular shell provides better confinement for the concrete, while concrete restrains the local buckling of the steel. The main cause of this is the lack of economical connections adapted to the circular shape of the column; and therefore, most connections require on-site welding.

In the present paper, bolted connections with curved end plates and blind bolts are studied as a valuable alternative. Such connections were firstly developed by Gardner and Goldsworthy (1999). They examined works of Alostaz and Schneider (1996), in which weldable deformed bars were used to redistribute flange forces into the concrete core, and come up with the idea of a curved flange plated joint. This joint was bolted to the circular column by means of blind bolts, that allowed to eliminate on-site welding. Further study of Yao et al. (2008) showed that, in the curved T-stubs with three bolts in the row, the forces between the external and internal bolts distribute unevenly - internal bolts fail prematurely. Oktavianus et al. (2014) showed that, by increasing the bolt inclination angle $\alpha$ (Figure 1c), stiffness and resistance of the curved T-stub decrease. It also became clear through these works that the T-stub approach recommended in Eurocode 3 Part 1-8 (European Committee for Standardization, 2005) for flat end-plate could not be directly extended to curved T-stubs, but that blind bolting could be more easily accommodated. In this regard, Oktavianus et al. (2017) have developed a component model for pull-out behaviour of headed anchored blind bolts, which could be used to predict the strength of individual anchor bolts. Furthermore, Wang et al. (2009) tested not only joints with the extended

${ }^{*}$ Corresponding author. E-mail: andrej.mudrov@vilniustech.lt 
curved end plates, but also with flushed ones. Results from these tests were later used in a parametric study (Wang \& Zhang, 2017) which showed that bending resistance depends on the bolt preloading force.

This paper presents an analytical model for the prediction of the bolt forces in the curved T-stubs within the elastic range. For its validation, two connections with different initial bolt preloading forces were tested. Results show a good agreement, but the model still requires further development to take prying forces into account.

\section{Behaviour of curved T-stub in tension}

One of the most general ways to model the stiffness and the design resistance of joints is to use the component method. The fundamental idea of this method is that a joint can be represented by a set of individual springs (components). For conventional bolted joints between $\mathrm{H}$ or I profiles under bending moment, one of the most important components is the T-stub in tension which is used to evaluate not only the strength of the bolts, but also the strength of the end-plate in bending, as both failure modes are anyway associated to the development of prying forces.

On the contrary, curved end plate with the inclined bolts (Figure 1a) is a shell-like statically unsolvable system, which is under two-dimensional bending. As a result, bolts can experience not only the prying action, but also can be prone to shear. Such a system is too complex to be analysed in general terms and hence, to derive the equations, few simplifications were made:

- Prying forces are first assumed to be negligeable as a result of the "curvature effect" of the T-stub (Figure 1b). The validity of this assumption will be discussed later in the paper;

- With the account of symmetry, only a half of the Tstub is analysed;

- Three-dimensional shell is modelled as a two-dimensional arched-beam, which is then loaded with the generalized force $2 F$ (Figure 1c);

- Inclined bolts are replaced by a set of elastic spring supports respectively representing their axial $K_{n}$ (also called "normal") and shear $K_{t}$ (also called "transverse") stiffnesses;

- In the assumed absence of prying forces, the parts of the T-stub located "outside the bolts" are not at all subjected to forces; these parts are therefore not represented in Figure 1c.

Equations were derived for the two cases: rigid end plate and flexible arch. Arch flexibility results in additional thrust forces which decrease bolt axial forces and increase shear ones.

\subsection{Rigid end plate}

In the case the arch is considered as rigid (what may be assumed for rather thick plates), the main variables are the stiffness and the inclination angle of the supports (Figure 1c). The horizontal thrust force $H$ (Figure $2 a$ ) is here equal to zero and the equilibrium of the spring reactions writes:

$$
F=F_{n} \cos \alpha+F_{t} \sin \alpha .
$$

By using Hooke's law, one can find the deformation of each spring and express it through $\Delta$ - overall displacement of the T-stub (Figure 2b):

$$
\begin{aligned}
& \Delta_{t}=\frac{F_{t}}{K_{t}}=\Delta \sin \alpha ; \\
& \Delta_{n}=\frac{F_{n}}{K_{n}}=\Delta \cos \alpha,
\end{aligned}
$$

where: $K_{n}$ - stiffness of normal spring; $K_{t}$ - stiffness of transverse spring.

Then, from formulae (2) and (3):

$$
\frac{F_{t}}{K_{t} \sin \alpha}=\frac{F_{n}}{K_{n} \cos \alpha} \text {. }
$$

Finally, by combining the equilibrium (1) and (4), one can derive a formula for the prediction of the axial force in the bolts in the case of rigid T-tubs:

$$
F_{n}=\frac{F}{\cos \alpha+\frac{K_{t}}{K_{n}} \tan \alpha \sin \alpha}=\frac{F \cos \alpha}{\cos ^{2} \alpha+\frac{K_{t}}{K_{n}} \sin ^{2} \alpha} .
$$

But also, the shear force:

$$
F_{t}=\frac{F}{\sin \alpha+\frac{K_{n}}{K_{t}} \operatorname{ctg} \alpha \cos \alpha}=\frac{F \sin \alpha}{\sin ^{2} \alpha+\frac{K_{t}}{K_{n}} \cos ^{2} \alpha} .
$$

a)

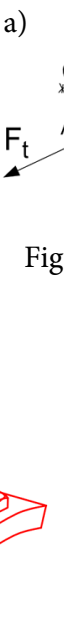

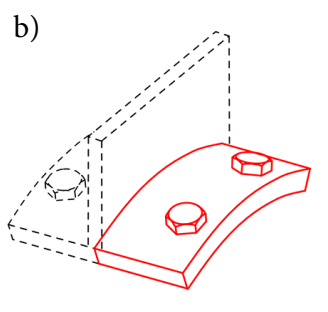

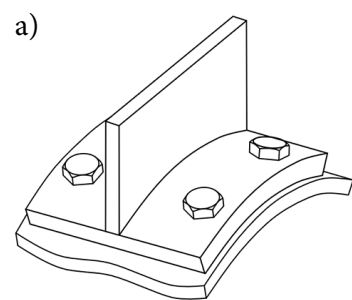

c)

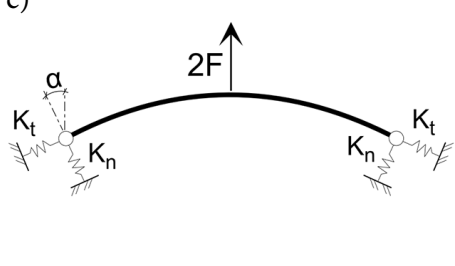

Figure 1. Simplification of the T-stub: a - curved T-stub; b - arched-beam; c - arch on spring supports 
Depending on the $K_{n} / K_{t}$ ratio, three boundary cases with constant $\alpha$ are identified (Figure 3), which represent three different support conditions.

When the transverse stiffness of the bolt is negligible in comparison to the normal stiffness $\left(\right.$ i.e. $\left.\frac{K_{t}}{K_{n}} \rightarrow 0\right)$, then the bolt axial force is $1 / \cos (\alpha)$ times greater than the applied external force, while the shear force is equal to zero. This happens because internal horizontal $H$ force is needed (Figure 4a) for this system to remain in equilibrium and not to slide down. In another case, when the bolts are rigid $\left(\right.$ i.e. $\left.\frac{K_{t}}{K_{n}} \rightarrow 1\right)$, then they can be substituted by pinned support and the external force will be vectorially decomposed into shear and tension (Figure $4 \mathrm{~b}$ ). And lastly, when the normal stiffness of the bolt is negligibly small $\left(\right.$ i.e. $\left.\frac{K_{t}}{K_{n}} \rightarrow \infty\right)$, then the bolts are subjected to a pure shear force which is $1 / \sin (\alpha)$ times greater than the applied external one (Figure 4c).

\subsection{Flexible arch}

When the curved end plate is flexible, then its own stiffness influences the T-stub response and needs therefore to be accounted for. In this case, the overall displacement of the supports will be affected by the horizontal transition $\Delta_{H}$ (Figure 5), which increases shear and decreases axial force:

a)

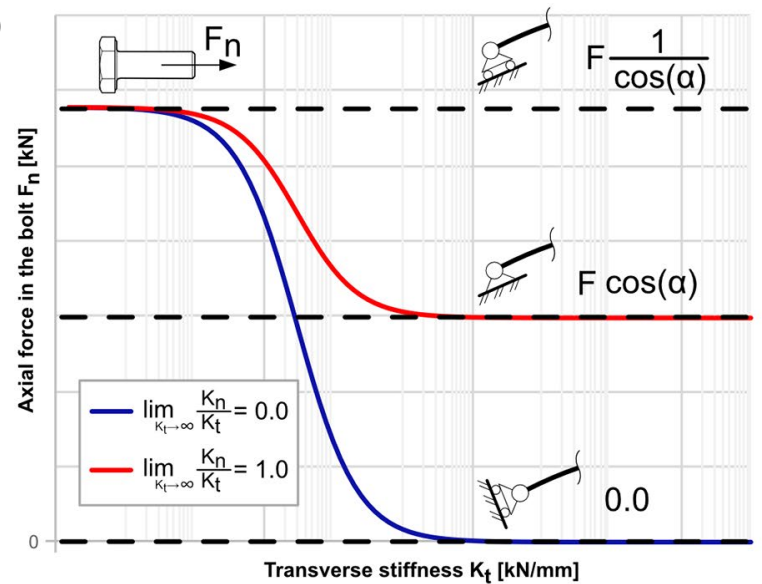

$\Delta_{t}=\frac{F_{t}}{K_{t}}=\Delta_{V} \sin \alpha+\Delta_{H} \cos \alpha$

$\Delta_{n}=\frac{F_{n}}{K_{n}}=\Delta_{V} \cos \alpha-\Delta_{H} \sin \alpha$.

Mathematically speaking, the equilibrium equation remains unchanged and only the physical equation expressing the compatibility of the displacements at the bolt location needs to be modified:

$$
\frac{F_{t}-\Delta_{H} \cos \alpha \cdot K_{t}}{K_{t} \sin \alpha}=\frac{F_{n}+\Delta_{H} \sin \alpha \cdot K_{n}}{K_{n} \cos \alpha} .
$$

The equations providing the reaction forces in flexible curved T-tubs are then the following ones:

$$
\begin{aligned}
& F_{n}=\frac{F-\Delta_{H} \sin \alpha \cdot K_{t}(\tan \alpha \cdot \sin \alpha+\cos \alpha)}{\cos \alpha+\frac{K_{t}}{K_{n}} \tan \alpha \sin \alpha}= \\
& \frac{F \cos \alpha-\Delta_{H} \sin \alpha \cdot K_{t}}{\cos ^{2} \alpha+\frac{K_{t}}{K_{n}} \sin ^{2} \alpha} ; \\
& F_{t}=\frac{F+\Delta_{H} \cos \alpha \cdot K_{n}(\operatorname{ctg} \alpha \cdot \cos \alpha+\sin \alpha)}{\sin \alpha+\frac{K_{n}}{K_{t}} \operatorname{ctg} \alpha \cos \alpha}= \\
& \frac{F \sin \alpha+\Delta_{H} \cos \alpha \cdot K_{n}}{\sin ^{2} \alpha+\frac{K_{t}}{K_{n}} \cos ^{2} \alpha} .
\end{aligned}
$$

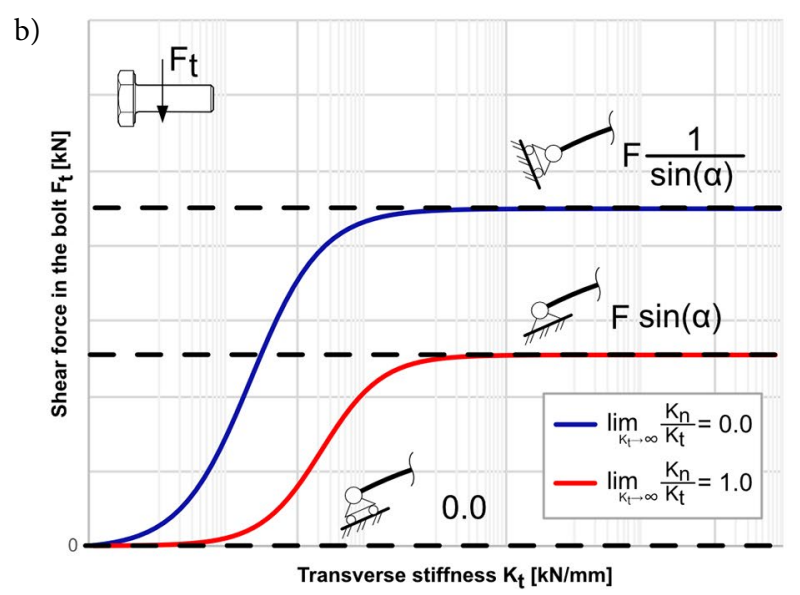

Figure 3. Effect of transverse stiffness on the: $a$ - axial force in the bolt; $b$ - shear force in the bolt

a)

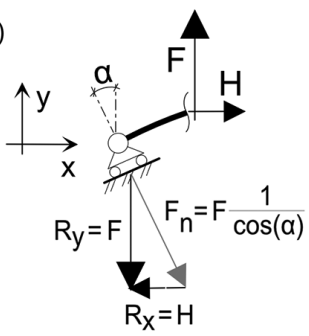

b)

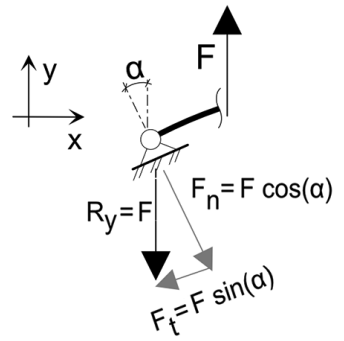

c)

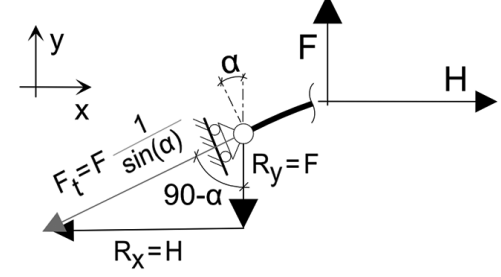

Figure 4. Support reactions: $\mathrm{a}$ - horizontally sliding support; $\mathrm{b}$ - pinned support; $\mathrm{c}$ - vertically sliding support 


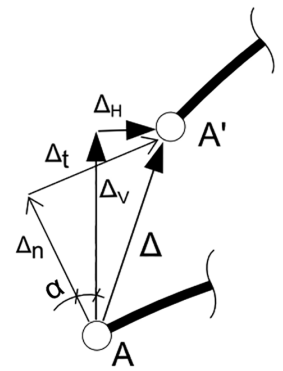

Figure 5. Support displacement in the case of a flexible T-stub

\subsection{Simplification}

In Eqns (10) and (11) the main unknown is the horizontal displacement $\Delta_{H}$. It depends on the geometry of the shell and its support conditions. In order to find $\Delta_{H}$, the T-stub of Figure 1c can be simplified with the alternative model, in which a set of inclined springs is replaced by one horizontally sliding support (Figure 6). To do so, resultant stiffness $K$ and support displacement $u$ should be found.

The resultant stiffness $K$ of the inclined springs may be derived by applying horizontal force $H$ to the support (Figure 7):

$$
\begin{aligned}
& K=\frac{H}{w}=\frac{H}{\Delta_{n} \sin \alpha+\Delta_{t} \cos \alpha}= \\
& \frac{H}{\frac{H \sin \alpha}{K_{n}} \sin \alpha+\frac{H \cos \alpha}{K_{t}} \cos \alpha}= \\
& \frac{K_{n} K_{t}}{\sin ^{2} \alpha \cdot K_{t}+\cos ^{2} \alpha \cdot K_{n}} \text {. }
\end{aligned}
$$

Moreover, to properly represent a set of inclined springs, sliding supports should be loaded with the displacement $u$ (Figure 8):

$$
\begin{aligned}
& u=\Delta_{t} \cos \alpha-\Delta_{n} \sin \alpha= \\
& \frac{F \sin \alpha}{K_{t}} \cos \alpha-\frac{F \cos \alpha}{K_{n}} \sin \alpha= \\
& F \frac{\sin \alpha \cdot \cos \alpha \cdot\left(K_{n}-K_{t}\right)}{K_{n} K_{t}} .
\end{aligned}
$$

It is caused by the external force $F$ and it is proportional to the vertical displacement $\Delta_{V}$. Due to this displacement, bolts are additionally loaded with shear.

\section{Experimental evaluation}

The test program was developed to explore the influence of the initial bolt preloading force on the behaviour of the joint. For this purpose, two connections between a circular concrete filled column and steel beams with the different bolt preloading forces were tested. The test setups and the geometry of the connection are respectively presented in Figure 9 and Figure 10. Properties of the materials used in the specimens were obtained experimentally and are presented in Table 1 and Table 2.

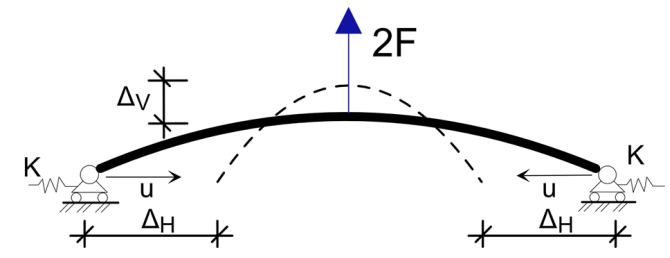

Figure 6. Simplified arch-beam model
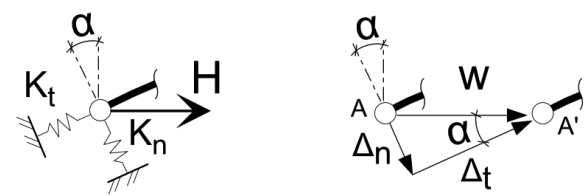

Figure 7. Calculation scheme of the resultant stiffness $K$
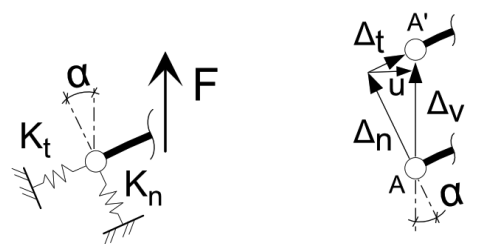

Figure 8. Calculation scheme of the displacement load $u$

Curved end plates were made from a seamless CHS $219 \times 10$ pipe, which was cut into four equal pieces; this tube was different from the one used to the column. Because of this, the curvatures of the end plate and of the circular column were not matching, and firm contact between them could not be achieved. The average throat thickness of the fillet weld joining the end plates with the IPE 270 beams was $4.44 \mathrm{~mm}$. The beams were connected to a cold formed CHS $219 \times 6$ column with four high strength M12 $\times 35 \mathrm{HV}$ bolts. The inclination angle of bolts was $23^{\circ}$ and the distance to the edge $-38 \mathrm{~mm}$ (Figure 10). In the last step, after assembly, columns were filled with concrete.

Forces in the high strength HV M12×35 10.9 bolts were measured with the imbedded BTMC-05-D10 axial strain gages. These strain gages were glued in $\varnothing 1 \mathrm{~mm}$ holes at the depth of $17 \mathrm{~mm}$ (from the bolt head). Before testing, each bolt was calibrated in the tensile machine by gripping bolt in special holders (Figure 9a). Bolts in the tension zone of specimen $1 \mathrm{~B}$ were prestressed to $0.7 \mathrm{fub}$ $(59 \mathrm{kN})$, while they were snug tightened to $1.5 \mathrm{kN}$ in specimen $4 \mathrm{~B}$.

Connection was loaded in successive steps - at the first step, an initial $500 \mathrm{kN}$ force in the column was introduced and maintained; then, at the second step, equal and opposite moments were induced by manually controlled hydraulic cylinders (Figure 10). Moreover, moments were applied in two cycles - the first cycle was meant for "exercise", so that bolts could take their proper position in the bolt holes, as much as to eliminate other minor out-ofmatching. Ends of the column were fixed and the ends of the beams were not restrained. 
Table 1. Mechanical and physical properties of the steel and fasteners

\begin{tabular}{|c|c|c|c|c|c|c|}
\hline \multirow[t]{2}{*}{ Index } & \multicolumn{2}{|c|}{ End-plate steel P355N (4 tests) } & \multicolumn{2}{|c|}{ Steel of CHS S235 (4 tests) } & \multicolumn{2}{|c|}{$\begin{array}{l}\text { High-strength bolts M12×35 } 10.9 \mathrm{HV} \\
\text { (4 tests) }\end{array}$} \\
\hline & Average & Standard deviation & Average & Standard deviation & Average & Standard deviation \\
\hline Yield strength & $389.8 \mathrm{MPa}$ & $4.30 \mathrm{MPa}$ & $318.8 \mathrm{MPa}$ & $21.52 \mathrm{MPa}$ & - & - \\
\hline Ultimate strength & $551.9 \mathrm{MPa}$ & $2.83 \mathrm{MPa}$ & $419.6 \mathrm{MPa}$ & $11.28 \mathrm{MPa}$ & $1147 \mathrm{MPa}$ & $14.31 \mathrm{MPa}$ \\
\hline Modulus of elasticity & $280.2 \mathrm{GPa}$ & $16.10 \mathrm{GPa}$ & $151.6 \mathrm{GPa}$ & $5.63 \mathrm{GPa}$ & - & - \\
\hline
\end{tabular}

Table 2. Mechanical and physical properties of the $10 \times 10 \times 10 \mathrm{~cm}$ concrete cubes

\begin{tabular}{|c|c|c|c|c|c|}
\hline \multirow{2}{*}{ № } & \multirow{2}{*}{ Specimen } & \multicolumn{2}{|c|}{ Compressive cube strength, MPa } & \multicolumn{2}{c|}{ Density, kg/m ${ }^{3}$} \\
\cline { 3 - 6 } & & Average & Standard deviation & Average & Standard deviation \\
\hline 1 & IB (8 tests) & 39.7 & 1.9 & 2318 & 12.9 \\
\hline 2 & IVB (8 tests) & 30.6 & 1.2 & 2351 & 17.6 \\
\hline
\end{tabular}

a)

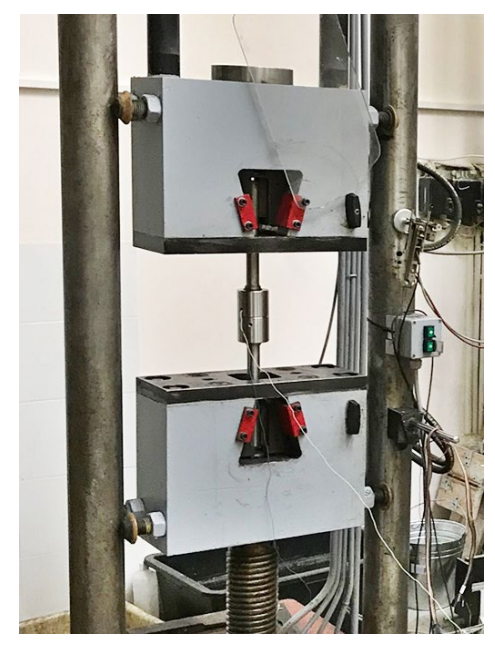

b)

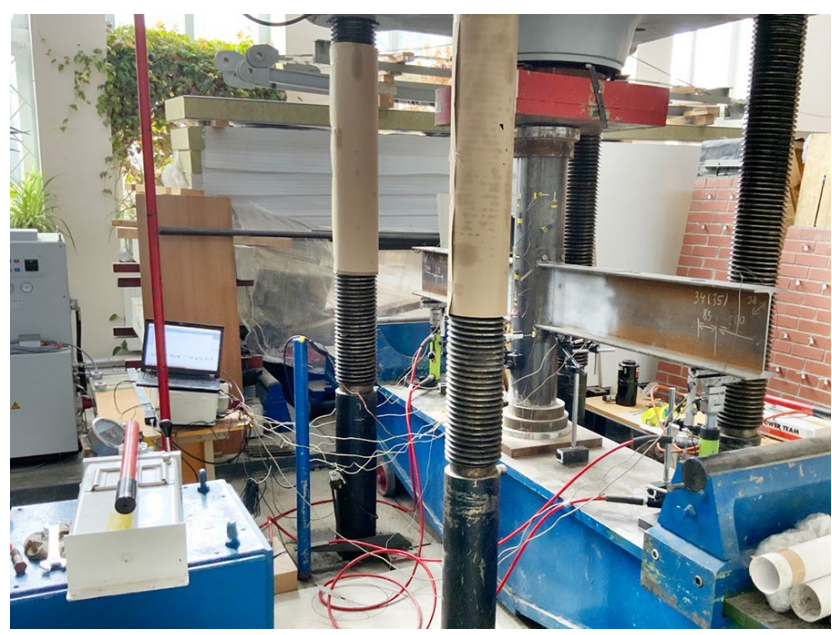

Figure 9. Testing rigs: a - bolt calibration setup; b - test stand

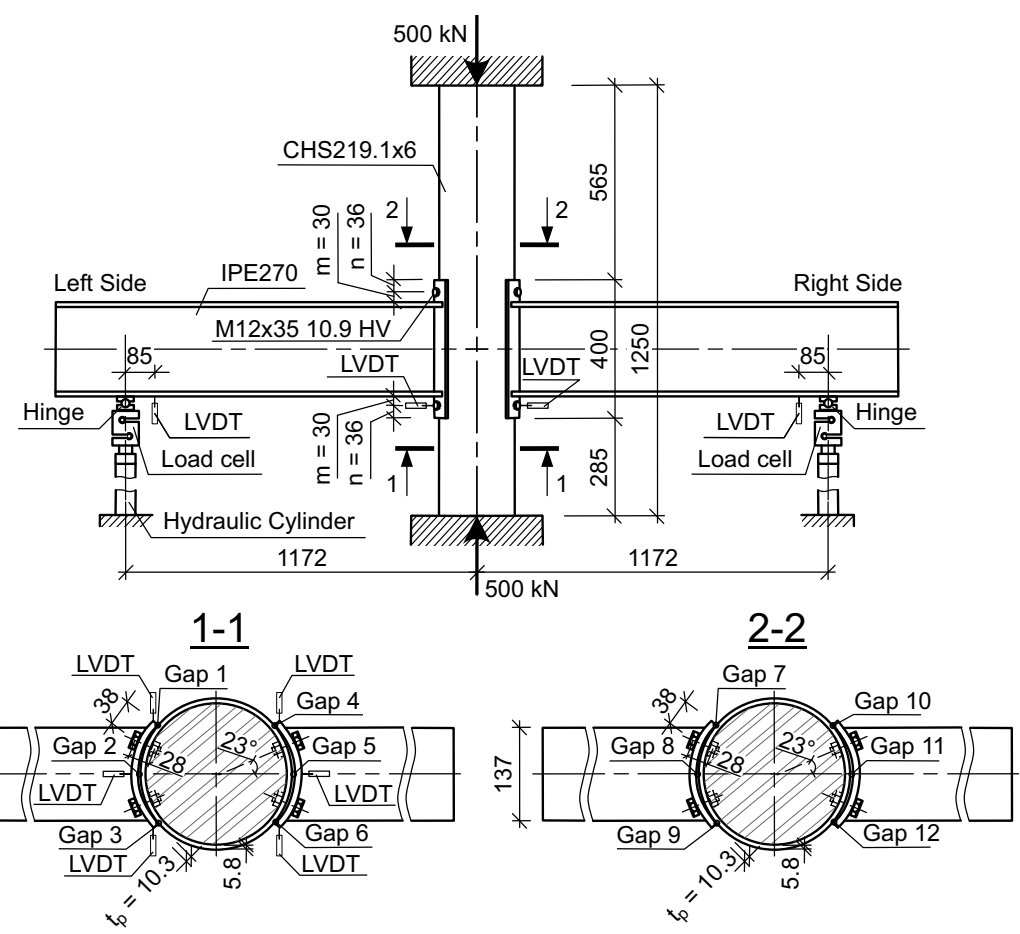

Figure 10. Geometry of the connection 
Vertical displacements of the beams were measured with two linear variable differential transformers (LVDT), which were placed on the bottom flange near the loading points. Horizontal displacements of the end plates in tension zone were measured by placing LVTDs in the middle of the bolt spacing and at the sides of the end plate (Figure 11). As the contact of the end plate and the column was not firm, the gaps between them were measured with the feeler gages (Figure 12). Moment-rotation curves are shown in Figure 13.

The ultimate bending resistance of the joints with initial preload is the same as for snug tightened connections, but elastic bending resistance is much higher (Figure 13). All connections failed due to punching shear (Figure 14a). Unscrewed bolts from tension zone were heavily bend because of displacement $u$ (Figure 8) associated with the deformations $\Delta_{V}$ (Figure 16b).
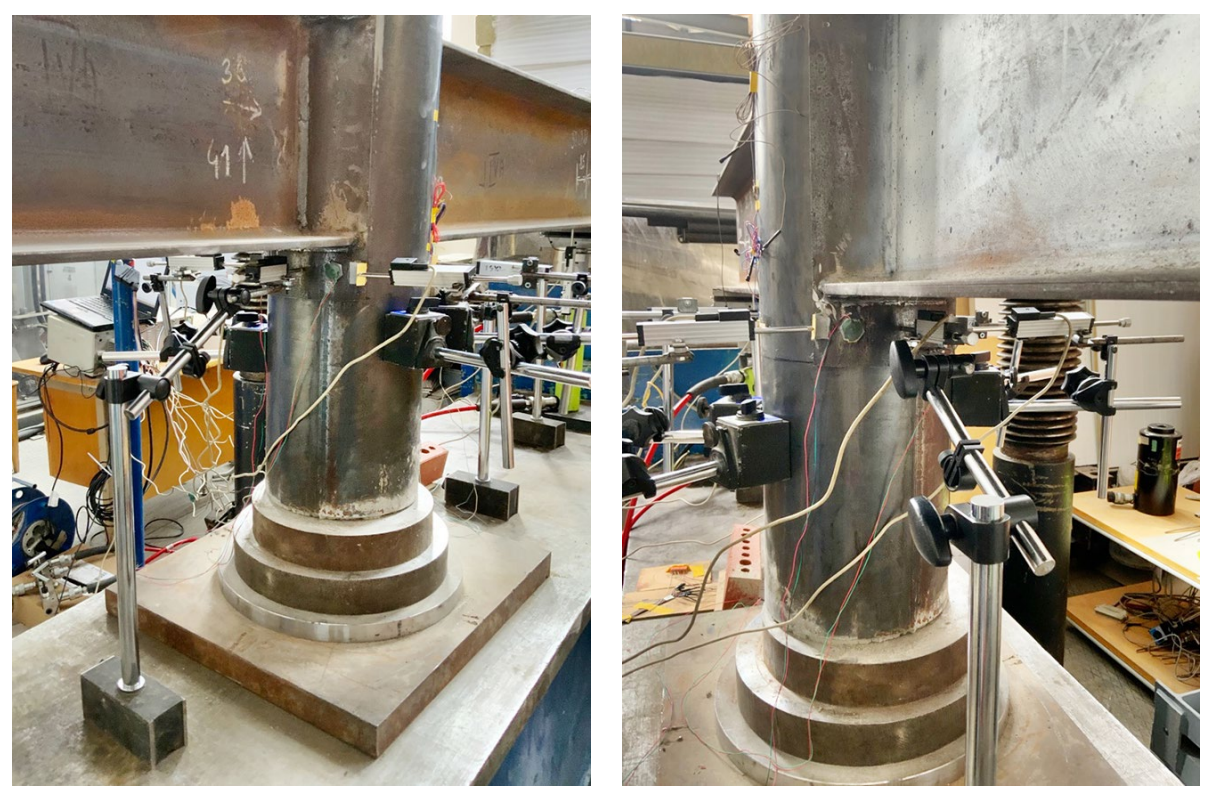

Figure 11. Placement of LVDTs in the tension zone of the joint

a)

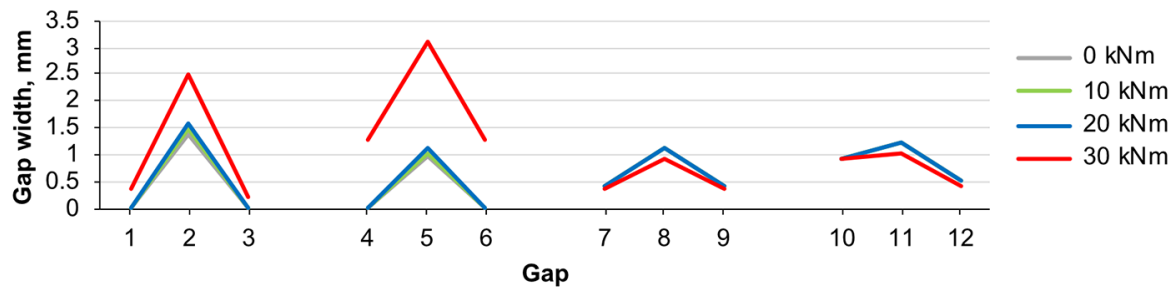

b)

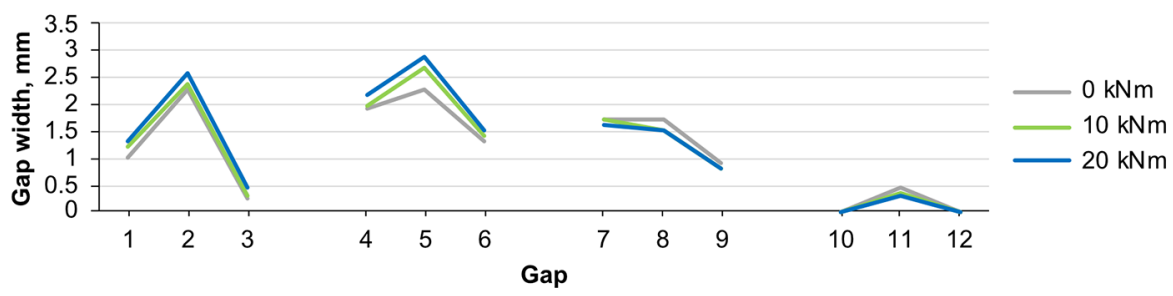

Figure 12. Gaps between the end-plate and the column (numbered according to Figure 10): $\mathrm{a}$ - connection $1 \mathrm{~B}$ (preloaded bolts); $\mathrm{b}$ - connection $4 \mathrm{~B}$ (snug tightened bolts) 
T-stub in tension component was so calculated with the expression:

$$
F_{\text {ext. }}=\frac{F \cdot\left(L-0.5 D_{0}\right)}{z}
$$

where: $F$ - applied load; $L$ - distance from loading points to the axis of the column; $D_{0}$ - outer diameter of column; $z$ - lever arm of joint.

Tightening of the M12 bolts was carried out with the regular wrench using the extension. Without an extension, the full-strength torque resulted only in a $30 \mathrm{kN}$ preloading force $\left(0.36 f_{u b}\right)$. In the process of preloading, two strain gages in bolts 2 and 4 were damaged. Furthermore, first loading cycle resulted in slips which caused relaxation of initial preloading force: in bolt 3 , the preload decreased from $55.7 \mathrm{kN}$ to $50.6 \mathrm{kN}(-9.2 \%)$ and in bolt 1 , the force decreased from $59.9 \mathrm{kN}$ to $44.4 \mathrm{kN}(-25.9 \%)$.

At the initial loading phase, $\Delta_{H}$ deformations of the end plate were negligibly small (Figure 16a) and, because of this, the theoretical model for the case of rigid end plates was used. In Figure 16a, deformations of the joint
$4 \mathrm{~B}(\mathrm{R})$ are not shown, as they were faulty. Theoretical bolt forces were determined with Eqn (5) in which the normal stiffness $K_{n}$ was calculated by cumulating the stiffness $k_{10}$ of the bolt in tension and the stiffness $k_{t w}$ of the tube wall under transverse tension:

$$
K_{n}=\left(\frac{1}{k_{10}}+\frac{1}{k_{t w}}\right)^{-1} .
$$

Stiffness of the bolt in tension was determined according to EC-3 (European Committee for Standardization, 2005) provisions. In the case of snug tightened connection, because there was no contact between the end plate and the column (Figure 12b), prying forces could not develop and therefore, the 1.6 factor from EC-3 was omitted, and stiffness of the bolt was calculated with:

$$
k_{10}=\frac{A_{s}}{L_{b}} E_{b},
$$

where: $A_{s}$ - bolt tensile stress area; $L_{b}$ - bolt elongation length (bolt grip length); $E_{b}$ - modulus of elasticity of the bolt.

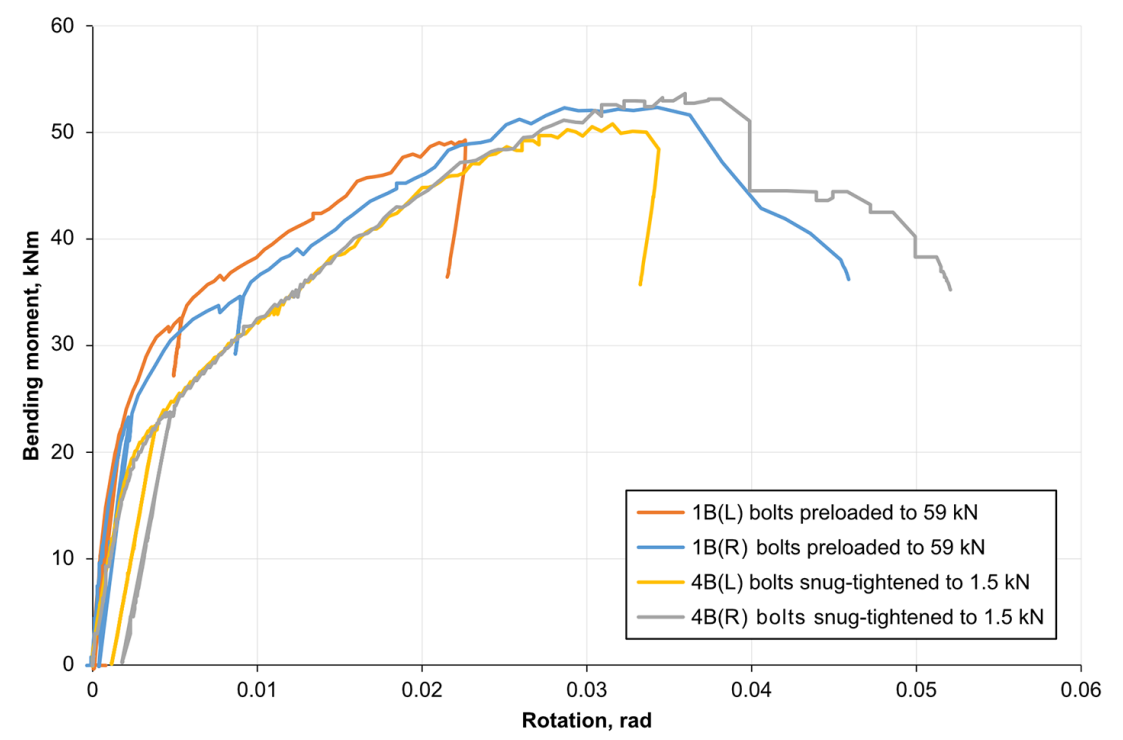

Figure 13. Moment rotation curves

a)

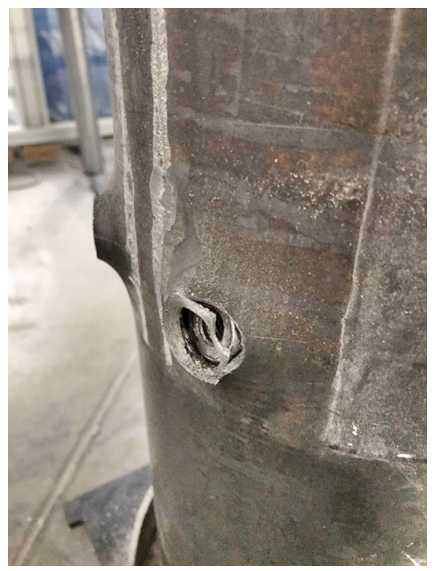

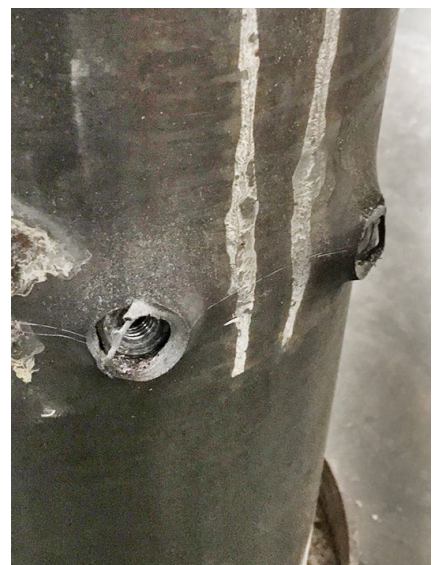

b)

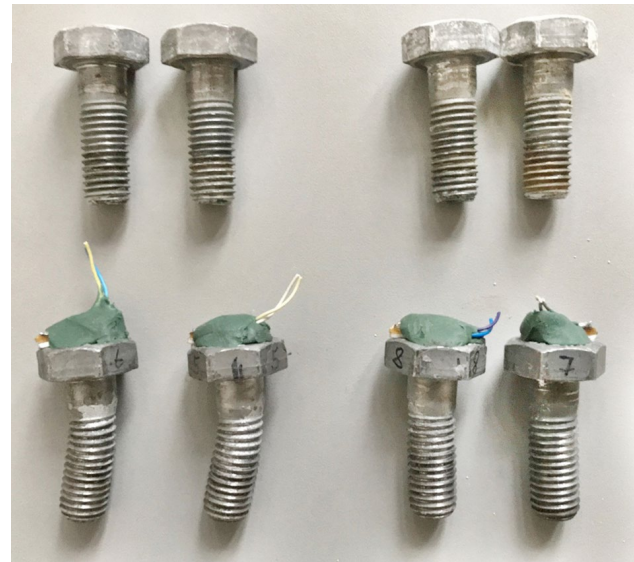

Figure 14. Failure mode: $\mathrm{a}$ - punching shear of the column wall; $\mathrm{b}$ - deformed bolts (top row - bolts from compression zone; bottom row - bolts from tension zone) 


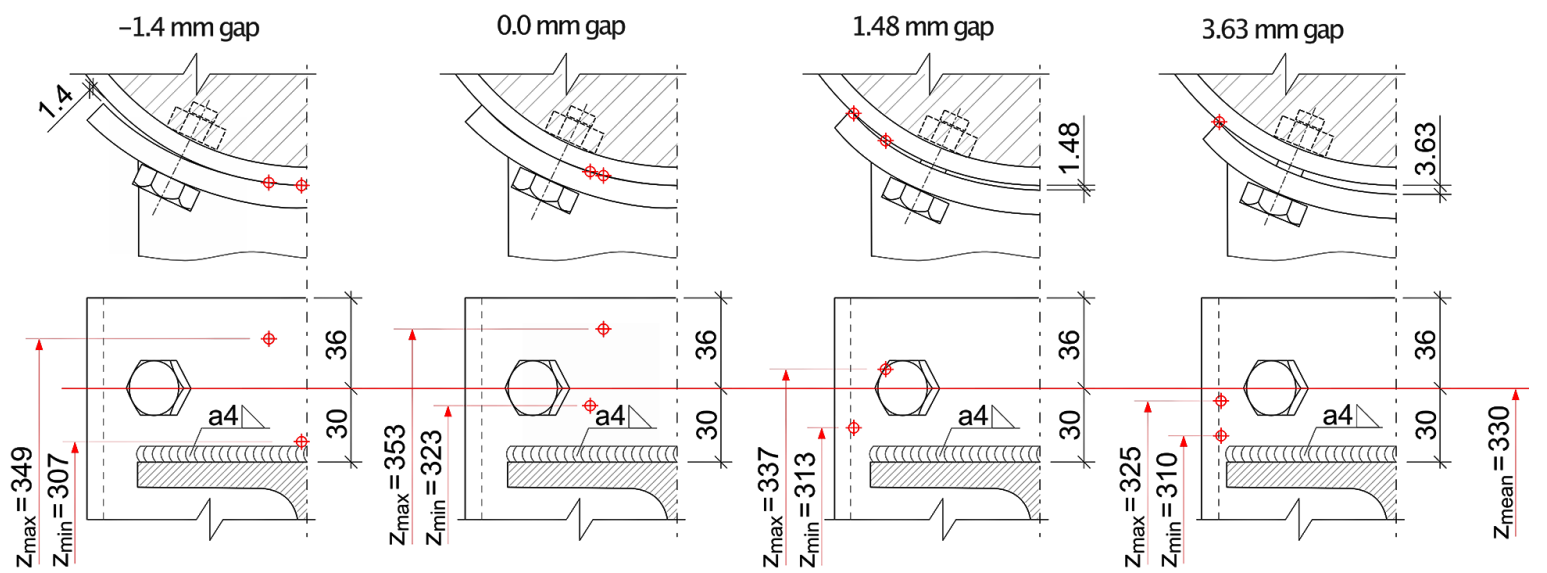

Figure 15. Position of the centre of compression (Mudrov et al., 2021)

a)

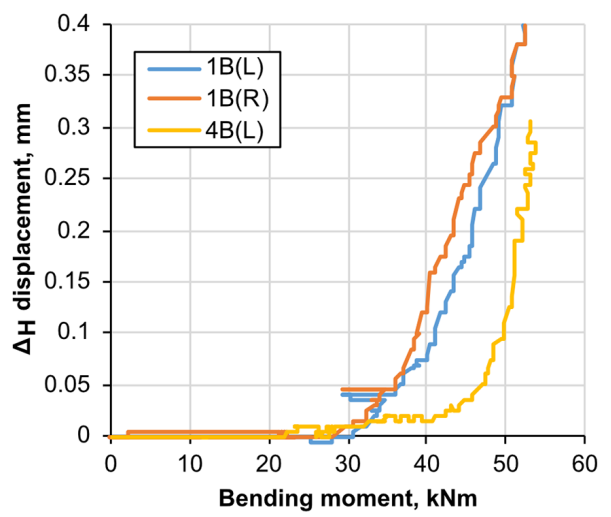

b)

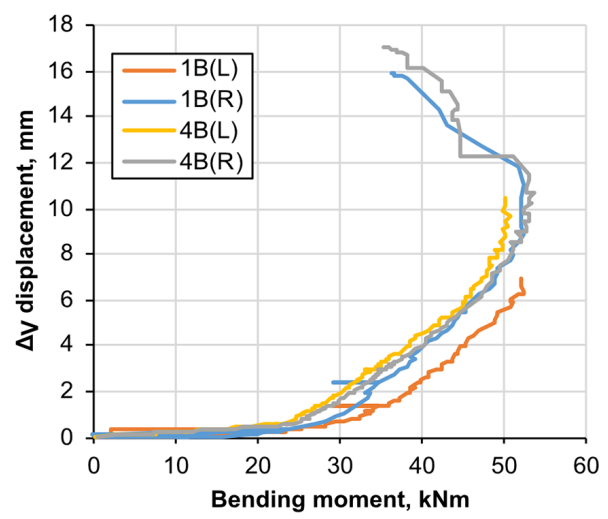

Figure 16. Displacement of the end plate in the tension zone of the joint: $\mathrm{a}-\Delta_{H}$; $\mathrm{b}-\Delta_{V}$

This absence of contact explains in fact why the model "without prying forces" presented in Section 1 of the paper can be used here to predict the results of the tests described in Section 2.

Stiffness of the tube wall $k_{t w}$ under transverse tension was calculated with a formula from Oktavianus et al. (2017):

$$
k_{t w}=\frac{\pi E_{t w} t_{t w}^{2}}{6\left(1-v^{2}\right) D_{0}}\left(\frac{d_{w s}}{d_{\text {hole }}}\right)^{4},
$$

where: $E_{t w}-$ modulus of elasticity of the steel tube; $t_{t w}-$ thickness of the tube; $v$ - Poisson's ratio of the steel tube; $D_{0}$ - outer diameter of steel tube wall; $d_{w s}$ - diameter of the nut; $d_{\text {hole }}$ - diameter of the bolt hole.

Transverse stiffness, in the case of the connection with the preloaded bolts, can be considered as infinite $\left(K_{t}=\infty\right)$. For the case of snug tightened bolts, EC-3 provisions were used:

$$
K_{t}=\left(\frac{1}{k_{11}}+\frac{1}{k_{12 . t p}}+\frac{1}{k_{12 . t w}}\right)^{-1} .
$$

The stiffness of the bolt in shear equals:

$$
k_{11}=\frac{8 d^{2} f_{u b}}{16 \mathrm{~mm}},
$$

where: $d$ - nominal bolt diameter; $f_{u b}$ - bolt ultimate tensile strength.
The stiffness of the bolt which is bearing on the end plate is defined as:

$$
k_{12 . t p}=12 k_{b} k_{t p} d f_{u . t p},
$$

where: $k_{b}=0.25 e_{b} / d+0.5 \leq 1.25 ; e_{b}$-distance from the bolt to the free edge of the end plate in $\Delta_{H}$ direction; $k_{t p}=1.5 t_{p} / 16 \mathrm{~mm} \leq 2.5 ; t_{p}$ - the thickness of the end plate; $f_{u . t p}-$ ultimate tensile strength of the end plate.

And finally, the stiffness of the bolt which is bearing on the tube wall is:

$$
k_{12 t w}=12 \cdot 1.25 k_{t w} d f_{u . t w}
$$

where: $k_{t w}=1.5 t_{t w} / 16 \mathrm{~mm} \leq 2.5 ; t_{t w}$ - tube wall thickness; $f_{\text {u.tw }}$ - ultimate tensile strength of the tube.

Comparison of experimentally obtained bolt forces and theoretical model is presented in Figure 17, in which limit values of individual fastener resistances were calculated with nominal values of yield strength and the ultimate tensile strength according to EC-3 (European Committee for Standardization, 2005).

In Figure 17 dotted lines denote points of the graph at which external applied force per bolt is equal to the axial bolt force. Theoretical bolt force was expressed with Eqn (5) as a function of external load. This function is a straight line, with the slope of 1.056 , which means that the theoretical bolt force is 1.056 times greater than the external load. 
a)

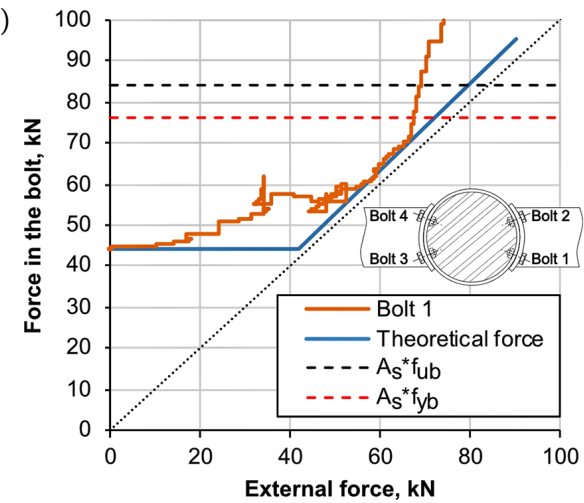

c)

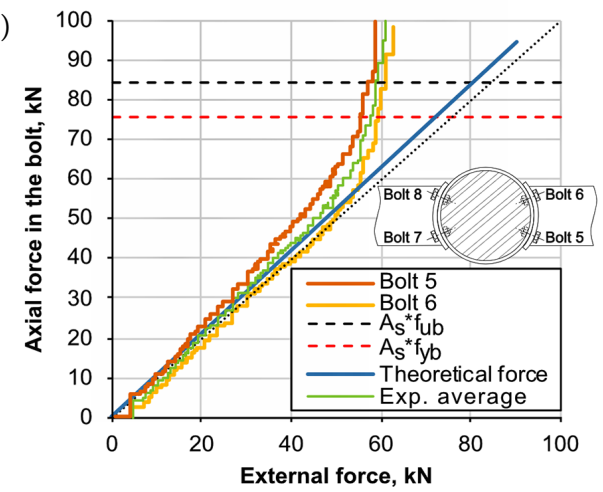

b)

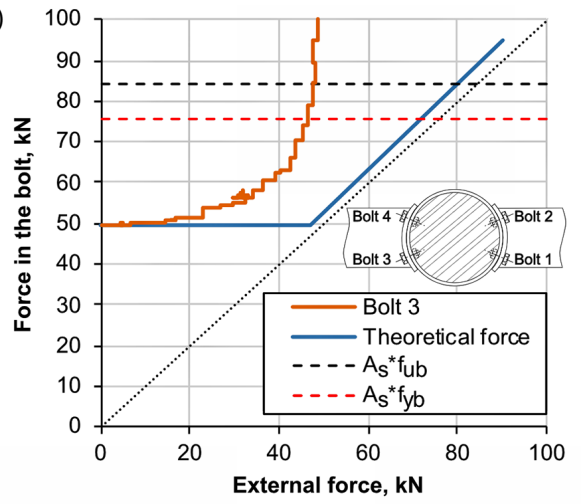

d)

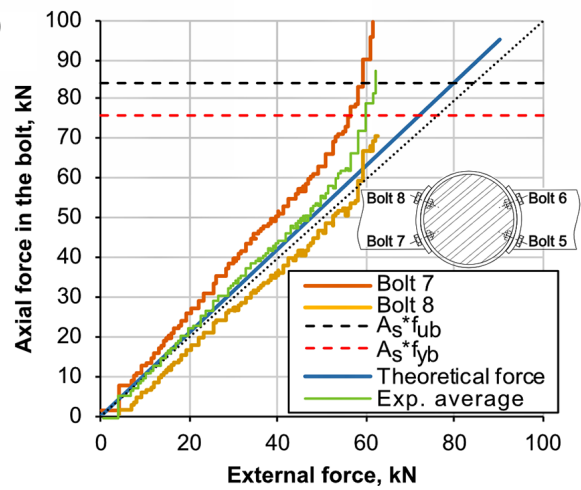

Figure 17. Comparison of experimental and theoretical (Eqn (5)) bolt forces in joints: $a-1 B(L) ; b-1 B(R) ; c-4 B(L) ; d-4 B(R)$

Looking at Figures $17 \mathrm{c}$ and $17 \mathrm{~d}$, in which bolts were snug tighten, it can be seen that joints experienced out-ofplane bending, as forces in adjacent bolts were not equal. To eliminate this out-of-plane moment, the average value of the force in adjacent bolts was taken. As it was predicted, experimental bolt force was greater than applied load. Further corelation-regression analysis of these average lines showed, that the slope of the regression line was 1.134 for the left joint and 1.180 for the right with corelation of 0.999 in both cases. As such, experimental slopes are only $9 \%$ higher than predicted.

Unfortunately, due to damaged strain gages in bolts 2 and 4 , joints with preloaded bolts (Figures 17a and 17b) cannot be properly analysed. It was predicted, that before the slip increase in axial bolt force would be zero, and after the slip and separation, behaviour of joint with preloaded bolts would be similar to snug tightened joint, which was confirmed.

\section{Conclusions}

This paper proposed an analytical model for the evaluation of bolt forces in the curved T-stubs with rigid or flexible end plates, but within the elastic range. Moreover, simplifications for hand calculations were suggested. Analytical formulas were compared against experimental results of joints between a circular concrete filled steel column and steel beams with both preloaded and snug tightened bolts subjected to bending. Experiments confirmed that increase in preloading force results in increased elastic bending resistance, while ultimate bending resistance remains not affected. After preloading has disappeared, such connections behave as slip resistant, but slip due to unfirm contact can result in significant loss of initial preloading force (more than 25\%). This suggests that more researches are needed in the extend of bolt force relaxation. The proposed analytical model shows good agreement with experimental data, but it requires further development to account for the prying forces, because they were neglected in this study, due to the initial unfit of the connected columns and curved T-stubs.

\section{References}

Alostaz, Y. M., \& Schneider, S. P. (1996). Analytical behavior of connections to concrete-filled steel tubes. Journal of Constructional Steel Research, 40(2), 95-127.

https://doi.org/10.1016/S0143-974X(96)00047-8

European Committee for Standardization. (2005). Eurocode 3: Design of steel structures - Part 1-8: Design of joints (EN 19931-8:2005/AC:2009).

Gardner, A. P., \& Goldsworthy, H. M. (1999). Moment-resisting connections for composite frames. In Proceedings of Conference on Mechanics of Structures \& Materials (pp. 309-314), Rotterdam, Netherlands.

Mudrov, A., Šapalas, A., Šaučiuvènas, G., \& Urbonas, K. (2021). Moment resisting connection with curved endplates: Behaviour study. Applied Sciences, 11(4), 1520.

https://doi.org/10.3390/app11041520

Oktavianus, Y., Goldsworthy, H. M., \& Gad, E. F. (2014, 21-23 November). Behaviour of headed anchor blind bolts embedded in concrete filled circular hollow section column. In Australian Earthquake Engineering Society 2014 Conference, Lorne, Victoria. 
Oktavianus, Y., Chang, H., Goldsworthy, H. M., \& Gad, E. F. (2017). Component model for pull-out behaviour of headed anchored blind bolt within concrete filled circular hollow section. Engineering Structures, 148, 210-224. https://doi.org/10.1016/j.engstruct.2017.06.056

Wang, J. F., Han, L. H., \& Uy, B. (2009). Behaviour of flush end plate joints to concrete-filled steel tubular columns. Journal of Constructional Steel Research, 65(4), 925-939. https://doi.org/10.1016/J.JCSR.2008.10.010

Wang, J., \& Zhang, N. (2017). Performance of circular CFST column to steel beam joints with blind bolts. Journal of Constructional Steel Research, 130, 36-52. https://doi.org/10.1016/j.jcsr.2016.11.026

Yao, H., Goldsworthy, H., \& Gad, E. (2008). Experimental and numerical investigation of the tensile behavior of blind-bolted T-stub connections to concrete-filled circular columns. Journal of Structural Engineering, 134(2), 198-208.

https://doi.org/10.1061/(ASCE)0733-9445(2008)134:2(198) 